\title{
Análise do processo de mudança semântica dos advérbios "literalmente" e Buchstäblich a partir do modelo semântico-cognitivo de Sweetser (1990)
}

An analysis of the semantic change process of the adverbs literally and Buchstäblich from Sweetser's (1990) cognitive-semantic model

\author{
Aline Deosti \\ Jean Diogo \\ Kayron Beviláqua \\ Ligia Negri \\ Silvia Bernsdorf \\ Universidade Federal do Paraná - UFPR - Curitiba - Paraná - Brasil \\ Jan Gisske \\ Universidade de Leipzig - Leipzig - Alemanha \\ Universidade Federal do Paraná - UFPR - Curitiba - Paraná - Brasil
}

\begin{abstract}
Resumo: Neste artigo, analisamos o advérbio do Português Brasileiro "literalmente" a partir dos pressupostos teóricos de Sweetser (1990). A análise é precedida de uma delimitação da classe dos advérbios segundo a "Gramática do Português Culto Falado no Brasil" (2008) e de uma apresentação dos principais conceitos de Sweetser. Em seguida, o advérbio "literalmente" é analisado a partir de casos extraídos do uso vernacular, alguns deles obtidos na internet. A análise é, então, estendida ao advérbio correspondente na língua alemã, buchstäblich, visando corroborar a aplicabilidade do modelo cognitivo como instrumental para a análise de mudança semântica.
\end{abstract}

Palavras-chave: Semântica Cognitiva. Metáfora. "Literalmente". Buchstäblich.

\begin{abstract}
In this paper, we analyze the Brazilian Portuguese adverb "literally" from Sweetser's (1990) perspective of Cognitive Semantics. The analysis is preceded by a definition of the adverbial class and a presentation of Sweetser's main concepts. Finally, the adverb "literally" is analyzed over some of its appearances in the vernaculum, including uses found in the internet. Then we extend the analysis to the correspondent German adverb, buchstäblich, aiming to corroborate the applicability of cognitive models to semantics changes.
\end{abstract}

Keywords: Cognitive Semantics. Metaphor. "Literalmente". Buchstäblich. 


\section{Introdução}

O objetivo do presente artigo é fazer uma análise semântica do advérbio "literalmente" no Português Brasileiro (PB), a partir do modelo cognitivo de semântica apresentado por Sweetser (1990). Considerando-se o papel central da metáfora nesse modelo, a escolha do advérbio "literalmente" foi motivada pela observação de que ele próprio pode ser utilizado de modo não literal, isto é, ainda que sua função mais comum seja a de denotar sentidos literais, ele comumente é utilizado em sentido metafórico. Ademais, tendo em vista que toda classificação de palavras é subsidiada por um modelo teórico, iniciaremos o texto delimitando a classe dos advérbios segundo a Gramática do Português Culto Falado no Brasil (CASTILHO et al., 2008).

Em seguida, apresentaremos o modelo de Sweetser (1990), ilustrado por exemplos da língua portuguesa extraídos de Augusto Soares da Silva (2006). Os conceitos apresentados serão utilizados em uma análise do advérbio "literalmente" no PB, aplicados a casos construídos a partir do uso vernacular, bem como a exemplos extraídos da internet. Por fim, estenderemos nossa análise ao seu correspondente na língua alemã, buchstäblich, acreditando que a busca por paralelos em diferentes línguas corrobora a aplicabilidade do modelo cognitivo como instrumental para a análise semântica.

\section{A classe dos advérbios}

Segundo Castilho et al. (2008), ainda que os advérbios frequentemente se apresentem no PB como palavras invariáveis que acompanham verbos, adjetivos ou outros advérbios, sua categoria não é bem delimitada. Mesmo dentre os advérbios terminados em -mente, podemos constatar uma ampla variação em sua distribuição, desafiando a definição que acabamos de mencionar. As seguintes sentenças, retiradas de Castilho et al. (2008, p. 404), ilustram esse fato:

(a) "nós aqui ficamos mais autenticamente brasileiros"; (b) "porque essa pessoa provavelmente será um cliente futuro";

(c) "pr'eu ter oportunidade de almoçar em casa... porque... justamente por esse meu problema".

Enquanto na sentença (a) a ocorrência do advérbio opera sobre um adjetivo; na sentença (b), o escopo de aplicação do advérbio é o predicado inteiro, um VP; enquanto na última sentença, (c), o advérbio incide sobre um sintagma circunstancial, um PP.

A complexidade cresce ao constatarmos que 0 escopo de aplicação dos advérbios vai além de verbos, adjetivos e outros advérbios, podendo, em algumas ocasiões, aplicar-se sobre a sentença como um todo e, em outras, até mesmo sobre os nomes.

O exame dos fatos mostra que os advérbios
podem igualmente aplicar-se aos nomes, mas
isso só ocorre em expressões de corte
metafórico, tais como: ele é muito homem,
muito gente, no sentido de 'muito viril, muito
generoso'; grosso modo, temos uma
interpretação de adjetivo para o nome escopo
do advérbio (CASTILHO et al., 2008, p. 406 ,
grifos do autor).

Abordaremos adiante a questão dos usos metafóricos e performativos dos advérbios. Por ora, diante de todas as aplicações possíveis dessas palavras tradicionalmente classificadas como advérbios, é interessante observar, além de seu escopo, a função que desempenham. Quando aplicados sobre os verbos, os advérbios possuem uma função modificadora, isto é, de modificação dos verbos. Seu efeito, segundo Castilho et al. (2008, p. 408), consiste em "acrescentar ao verbo propriedades semânticas de que ele não dispõe" enquanto item lexical. O advérbio bruscamente, quando aplicado sobre o verbo "frear", especifica um modo de frear, ou seja, ele predica o verbo "frear", conferindo-Ihe o sentido específico de "frear bruscamente".

Nem todo advérbio, é verdade, possui essa propriedade de qualificar verbos, mas os autores ressaltam o fato de que, em geral, eles podem ser vistos como operadores semânticos. Isso justificaria porque palavras tão distintas como rapidamente, muito e sempre podem ser consideradas pertencentes a uma 
mesma classe a despeito de sua dissimilaridade morfológica (e, por essa mesma razão, os autores sugerem que se trate separadamente advérbios indexicais tais como aqui e hoje, que se apresentam mais frequentemente como argumento do que como operadores). Uma vez estabelecida tal caracterização, podem-se estabelecer subclasses de advérbios de acordo com o efeito semântico que produzem. Assim, a Gramática do Português Culto Falado no Brasil (CASTILHO et al., 2008) distingue, no capítulo 5, os advérbios predicativos dos verificadores e dos circunstanciais e subdivide os primeiros em: qualificadores, aspectualizadores, modalizadores, graduadores e quantificadores.

É interessante observar a natureza semântica, e não essencialmente morfológica, dessa classificação. Advérbios com o sufixo -mente, por exemplo, estão presentes em mais de uma subclasse. "João canta desafinadamente" (CASTILHO et al., 2008, p. 413) é uma ocorrência qualificadora, enquanto "fazer uma dieta vegetariana eu acho válido, mas não permanentemente" (CASTILHO et al., 2008, p. 422) é aspectual durativa e "realmente... os filmes eram muito ruins" (CASTILHO et al., 2008, p. 425) é modalizadora. Os advérbios modalizadores possuem a notável característica de expressarem a atitude ou o grau de comprometimento do falante com a sentença proferida. Considere-se, por exemplo, o último dos três exemplos acima. Nele, o modalizador realmente expressa a constatação do falante de que os filmes eram muito ruins e sua concordância com essa afirmação funciona como um marcador de atitude proposicional. Um exemplo de ocorrência adverbial que expressa grau de comprometimento está na sentença "logicamente eu gostaria de fazer" (CASTILHO et al., 2008, p. 428). Aqui, o modalizador logicamente expressa necessidade/certeza de que 0 falante gostaria de fazer algo ou, ao menos, que ele se compromete discursivamente com o seu proferimento.

Castilho et al. (2008) ainda subdividem os advérbios predicativos modalizadores em três classes: epistêmicos, deônticos ou atitudinais. Os modalizadores epistêmicos expressam necessidade, possibilidade, certeza ou dúvidas: (d) Ele não está satisfeito. Provavelmente o filme foi ruim.

Os modalizadores deônticos expressam obrigação, volição, proibição e permissão:

(e) O valor do ingresso deverá ser ressarcido obrigatoriamente.

E os modalizadores atitudinais expressam 0 efeito psicológico que sentença produz no locutor ou nos interlocutores:

(f) Não estou satisfeito. Infelizmente o filme foi ruim.

Essa divisão, conforme veremos a seguir, aproxima-se muito da classificação de expressões predicativas sugerida por Sweetser (1990), que subdivide os termos modais em epistêmicos, deônticos e performativos. Na próxima seção apresentaremos o modelo da autora, a partir do uso de expressões modais, explicitando sua ligação com a cognição e a metáfora.

\section{0 modelo de Sweetser (1990)}

Sweetser (1990) opta por abordar o campo semântico a partir de uma abordagem cognitiva, sustentando que a linguagem é fundamentada na cognição humana e na experiência cotidiana e que uma abordagem cognitiva do significado poderia capturar a língua em sua dinâmica, dando conta de fenômenos amplos como a polissemia, a mudança semântica lexical e a ambiguidade pragmática. Tais fenômenos têm em comum o fato de apresentarem uma forma sendo utilizada em múltiplas acepções. Na polissemia, uma forma possui funções distintas em um mesmo recorte sincrônico. Na mudança, uma forma adquire funções distintas historicamente em um recorte diacrônico. Na ambiguidade pragmática, uma forma é estendida para exercer outras funções de acordo com determinado contexto: "we might say this is the case with a phrase like 'How are you?', which 
arguably retains its original sense as an inquiry about wellbeing, but is also conventionally situationally interpreted as a greeting or opener for an encounter"1 (SWEETSER, 1990, p. 1).

A autora observa ainda que a própria distinção entre forma e função reflete a organização cognitiva. "It should not be a controversial claim that relationships between linguistic form and function reflect human conceptual structure and general principles of cognitive organization"2 (SWEETSER, 1990, p. 4). Nesse intuito, a autora aponta algumas limitações da semântica formal e da gramática gerativa na explicação de fenômenos de mudança semântica, tendo em vista que tais abordagens privilegiam, cada uma a seu modo, os fenômenos sintáticos sobre os fenômenos semânticos, ora privilegiando 0 estudo das regularidades composicionais das sentenças em detrimento de seu uso, ora estabelecendo uma separação arbitrária entre semântica sincrônica e mudança histórica. A intenção de Sweetser não é sobrepujar tratamentos alternativos da mudança semântica, mas explorar um modelo que leve em conta as regularidades que podem ser observadas na percepção e no entendimento humanos. A semântica cognitiva, sustenta ela, capturaria a língua em sua deriva, incorporando em uma mesma explicação suas transformações nos domínios sincrônico e diacrônico.

Inicialmente, recorrendo a Saussure, Sweetser observa que, ainda que haja componentes de arbitrariedade na associação entre palavras e o que elas significam, os significados novos adquiridos por uma palavra não são arbitrários, isto é, existem razões pelas quais uma palavra pode passar a significar outras coisas além daquelas para as quais costumava ser designada.

In I see the tree, it is an arbitrary fact that the sequence of sounds which we spell see is used in English to refer to vision. But, given this

\footnotetext{
1 "Nós podemos dizer que este é o caso em uma frase como 'Como vai você?', que retém pouco de seu sentido original sobre bem-estar, mas é convencional e situacionalmente interpretada como um cumprimento ou como o princípio de um encontro." (Assim como essa, todas as citações extraídas de obras estrangeiras foram traduzidas livremente pelos autores em notas de rodapé.)

2 "Não seria controversa a reivindicação de que a relação entre forma e função linguísticas refletem a estrutura conceitual humana e os princípios gerais da organização cognitiva"
}

arbitrary fact, it is by no means arbitrary that see can also mean 'know' or 'understand,' as in I see what you're getting at. There is a very good reason why see rather than, say, kick or sit, or some other sensory verb such as smell, is used to express knowledge and understanding $^{3}$ (SWEETSER, 1990, p. 5).

Assim, a autora assume que a cognição molda a língua em alguma medida, de modo que certas regularidades podem ser identificadas no processo de mudança semântica e inicia uma exploração dos mecanismos cognitivos subjacentes ao processo de mudança/extensão dos significados de uma palavra. $\mathrm{E}$ desse modo, partindo não do mundo real, mas da percepção e da compreensão que o homem tem do mundo, a abordagem cognitiva encontra na metáfora o principal recurso explicativo para as regularidades observadas nas mudanças semânticas tanto diacrônicas quanto sincrônicas. Mais especificamente, a construção de significados, tanto na evolução histórica da língua quanto no desenvolvimento infantil, procede do concreto para o abstrato via metáfora. Tal processamento seria mobilizado por nossa tendência a aplicar o vocabulário concernente ao domínio externo quando falamos do domínio interno. "Metaphor allows people to understand one thing as another without thinking the two things are objectively the same"4 (SWEETSER, 1990, p. 8). Isso significa que as experiências físicas e interações sociais concretas constituem a base a partir da qual experiências abstratas podem ser significadas no nível lógico.

Sweetser (1990) estabelece então três níveis de construção do significado: (1) nível de conteúdo, fundamentado na experiência concreta social ou física, (2) nível epistêmico, fundamentado na experiência lógico-abstrata que estende o nível anterior, e (3) nível de ato de fala, que corresponde aos usos performativos dos termos significados nos níveis anteriores. Essa semântica tríplice pode ser ilustrada

\footnotetext{
3 "Em eu vejo a árvore, é um fato arbitrário que a sequência de sons ver seja usada em português para se referir à visão. Mas, dado este fato arbitrário, não é de modo algum arbitrário que ver pode também significar 'saber' ou 'entender', como em eu vejo o que você está querendo dizer. Existe uma boa razão pela qual ver, mais do que, digamos, chutar, sentar ou algum outro verbo sensorial como cheirar, é usado para expressar conhecimento ou entendimento"

4 "A metáfora permite às pessoas entender uma coisa como outra sem terem que pensar que ambas são objetivamente a mesma"
} 
por meio de expressões modais (pode, deve, tem que etc.), as quais são particularmente interessantes por revelarem uma ambiguidade entre o "externo" e o "interno". Seguindo o modelo de três níveis, os modais podem ser deônticos (no nível de conteúdo), epistêmicos ou ainda performativos. Os modais deônticos (ou root modals) expressam obrigação, permissão ou habilitação, enquanto os epistêmicos expressam necessidade, possibilidade ou certeza. $\mathrm{Na}$ sentença imperativa "Você deve sair agora! ", o modal deve está sendo utilizado de modo deôntico, isto é, no nível de conteúdo, pois o agente da elocução está dando a ordem para que alguém saia. Na sentença "Ele deve estar saindo agora", o modal deve estar sendo utilizado de modo epistêmico, pois o agente da elocução está falando sobre a possibilidade de que alguém esteja saindo no momento do proferimento da sentença.

Alguns casos de emprego de modais apresentam ambiguidade e sensibilidade ao contexto em relação a como devem ser interpretados. A sentença "Eles devem sair juntos do local" pode ser interpretada tanto uma ordem para que determinadas pessoas saiam juntas de um local, quanto como uma asserção acerca da possibilidade de que essas pessoas saiam juntas, i.e., "Provavelmente eles sairão juntos do local".

De modo similar, a sentença "Você deverá estar lá amanhã" pode ser interpretada como expressão de uma ordem ou, em outros contextos, de uma conclusão lógica. Este último exemplo de ambiguidade revela a similaridade que existe entre os domínios socio-físico e epistêmico. Ambas as interpretações apontam para uma necessidade, mas, na segunda, a necessidade está restrita ao campo lógico, como se o falante estivesse sendo compelido não a uma ação física, mas a uma conclusão. Enquanto ordem, "Você deverá estar lá amanhã" aponta para necessidade concreta, de ordem social, sugerindo ao interlocutor que ele tem o dever de estar em determinado lugar no dia seguinte. Já enquanto conclusão lógica, essa mesma sentença corresponde a uma constatação de que muito provavelmente seu interlocutor estará em determinado local no dia seguinte. No primeiro caso, trata-se de um falante compelindo seu interlocutor a algo, enquanto no segundo, o próprio falante é compelido a acreditar nesse mesmo algo.

A capacidade cognitiva de perceber a similaridade entre uma necessidade concreta e uma necessidade epistêmica é, de acordo com esse modelo, a essência da operação metafórica. Assim, através da metáfora o sujeito cria um paralelo das relações sociais e físicas do domínio concreto nas relações lógicas e abstratas do domínio epistêmico. Assim como ele pode ser compelido a efetuar um movimento, pode também ser compelido a uma conclusão. A similaridade perceptual entre tais compulsões permite-lhe aplicar o termo de um domínio a outro e tal transposição caracteriza a aplicação como metafórica.

A metáfora permite ainda estender a possibilidade de que expressões sejam usadas de modo performativo. No caso dos modais, isso significa que os termos podem ser destituídos de suas funções concreta e epistêmica no contexto de uso para modalizar a atitude proposicional do falante. Sweetser (1990) constrói o seguinte exemplo: na sentença "ele pode até ser professor", o modal pode pode ser interpretado como uma permissão (deontic modal, "eu o autorizo a ser professor") ou como uma constatação (epistemic modal, "é plausível que ele seja professor") e, em ambos os casos, o modal indicaria uma possibilidade. Suponha-se agora uma ocasião na qual, referindo-se a um professor de quem não gosta, um aluno diga: "ele pode até ser professor, mas é muito ignorante". Nesse caso, o termo pode está sendo utilizado sobre uma informação que se sabe ser correta, não indicando, portanto, possibilidade ou permissão. Sabendo que a pessoa em questão é um professor, são questionadas as inferências que daí decorrem, a saber, que 'ser professor' supõe não ser ignorante. O verbo foi destituído de suas significações concreta e epistêmica, adquirindo uma nova conotação que diz respeito ao ato de fala, de modo que a sentença poderia ser parafraseada como "apesar de ser professor, ele é muito estúpido".

Mas como pode, nesse caso, o exercício metafórico ter conduzido o falante do campo da 
possibilidade (de conteúdo ou epistêmica) para o campo performativo? Onde está a similaridade que viabiliza o salto de uma função para a outra? Existe uma interpretação intermediária que, embora especulativa, poderia indicar um caminho cognitivo possível de construção dessa metáfora: "para alguém que é professor, ele poderia ser menos estúpido". Nessa sentença, o modal foi reposicionado e recuperou seu caráter epistêmico original de denotar possibilidade, mas o caráter adversativo e a constatação de estupidez mantiveram-se preservados.

Em suma, o modelo cognitivo de Sweetser (1990) propõe uma análise unificada dos aspectos sincrônicos e diacrônicos do campo semântico, encontrando no processamento cognitivo da experiência com o mundo a raiz dos fenômenos de significação. Sweetser (1990, p. 12) argumenta: "I agree strongly with those who consider meaning to be rooted in human cognitive experience: experience of the cultural, social, mental, and physical worlds. But cognition is structured, not chaotic" ${ }^{\prime 5}$. A partir de uma vivência concreta é possível, graças a processos metafóricos, construir significados cada vez mais abstratos em uma sofisticada estrutura de inter-relação de expressões.

\begin{abstract}
Systematic metaphorical connections link our vocabulary of the sociophysical domain with the epistemic and speech-act domains. Thus, for example, is not by chance that must is polysemous between social obligation and logical certainty although it would be hard to find a common objective feature of these meanings ${ }^{6}$ (SWEETSER, 1990, p. 13).
\end{abstract}

Assim, os processos metafóricos se dispõem como um recurso explicativo geral para os fenômenos de mudança semântica, dado que revelam o caráter regular, ainda que convencionado e nem sempre previsível, de tais mudanças, que não se limitam ao âmbito lexical. É plausível supor que motivem também os fenômenos de mudança gramatical. A gramaticalização é, segundo Silva (2006, p. 102), um

\footnotetext{
5 "Eu concordo fortemente com aqueles que consideram o significado enraizado na experiência cognitiva humana: experiência dos mundos cultural, social, mental e físico. Mas a cognição é estruturada, não caótica."

6 "Conexões metafóricas sistemáticas ligam nosso vocabulário do domínio sócio-físico com os domínios epistêmico e
}

"processo pelo qual uma unidade lexical passa a assumir uma função gramatical ou uma unidade gramatical passa a assumir uma função ainda mais gramatical".

O autor apresenta alguns exemplos que ilustram a ocorrência desses processos na língua portuguesa, como a conjunção concessiva embora, que se originou da locução em boa hora. As frases "ele foi em boa hora [no tempo certo] para outro país", "ele foi embora [de vez] para outro país" e "ele foi, embora [ainda que] para outro país" dificilmente seriam consideradas sinônimas por falantes do português brasileiro contemporâneo. A transformação morfológica de em boa hora para embora e sua reanálise gramatical de locução adverbial para conjunção, bem como os processos pragmáticos que conduziram essas transformações, foram motivados justamente pelo mecanismo metafórico descrito por Sweetser anteriormente. Não por coincidência, Silva considera que:

O efeito capital da gramaticalização e da mudança semântica em geral é a subjetivação ou tendência para 0 envolvimento do conceptualizador/locutor naquilo que diz. [...] A subjetivação compreende as estruturas e estratégias envolvidas na realização linguística da subjetividade e os próprios processos de mudança semântica (SILVA, 2006, p. 104).

Ainda que o autor aproxime subjetivação e processos metonímicos, a descrição que ele oferece acima para o processo de subjetivação resguarda similaridades com a descrição que Sweetser faz do mecanismo metafórico pelo qual o mundo externo é modelado a partir do mundo interno. Mesmo que Silva busque distinguir categorias mais finas nos processos de mudança (metáfora, metonímia, generalização, especialização, subjetivação etc.), na base dessas distinções ele também sustenta que "os conceitos sóciomorais e psicológicos tendem a desenvolver-se a partir dos conceitos físicos" (SILVA, 2006, p. 108). Ademais, o autor privilegia a metáfora e a metonímia

performativo. Assim, por exemplo, não é por acaso que deve é polissêmico entre a obrigação social e a certeza lógica ainda que possa ser difícil encontrar uma característica objetiva comum desses significados" 
enquanto mecanismos que, diferentemente da generalização e da especialização, permitem a mudança de perspectiva diante dos domínios conceituais. A metáfora, em especial, permite o mapeamento entre dois domínios distintos, enquanto a metonímia opera dentro do mesmo domínio.

A bem-conhecida metáfora conceptual "compreender é ver", instanciada em expressões como "agora estou a ver o que me queres dizer", "lançar luz sobre o problema", "pensamento claro/obscuro", processa-se na base de várias projeções de atributos, entidades e proposições no domínio da visão para o domínio da compreensão.

O acto de ver corresponde ao acto de compreender; a pessoa que vê é a pessoa que compreende; um aumento de luminosidade corresponde a um aumento de compreensão; impedimentos de ver correspondem a impedimentos de compreender. [...] Assim como um objeto opaco não permite ver seu interior, assim também uma ideia ou conjunto de ideias não claramente expressas tornam-se difíceis de compreender; assim como mais iluminação conduz a melhor visibilidade, assim também mais esclarecimento permite uma melhor compreensão (SILVA, 2006, p. 122123).

Isso novamente coincide com o modelo de Sweetser (1990), que antecipou essa reflexão ao apontar em seu texto a função da metáfora na extensão dos verbos de percepção, os quais, através de analogias com a experiência corporal, nomeiam experiências perceptuais abstratas segundo um mapeamento que parte do domínio sensorial em direção ao domínio abstrato. Ambos são conceituais e subjetivos, mas as bases do processo, conforme afirmado por Sweetser, encontram-se nos domínios mais concretos. No caso do uso de ver como metáfora de entender, a cognição serve-se da similaridade que há entre tomar conhecimento de algo através da visão e tomar conhecimento de algo através de, por exemplo, uma descrição. A forma mais comum de identificação perceptual de um objeto se dá através da visão, daí a preferência a se utilizar termos relativos a esse sentido para significar, por exemplo, a identificação de um conceito: "eu vejo o que você quer dizer". Através de analogias similares, a experiência tátil pode ser utilizada para significar uma comoção: "fui tocado pela música"; e, a olfativa pode ser utilizada para significar uma investigação: "estou farejando um problema". Termos abstratos também podem admitir metaforicamente uma predicação sensorial conquanto resguardem alguma similaridade perceptual com a sensação da qual são predicados, como na expressão "temperamento amargo", que relaciona o temperamento de uma pessoa com certos aspectos desagradáveis de se experimentar algo amargo. De modo especulativo, pode-se dizer que essa analogia é favorecida por traços perceptuais tais como a expressão facial típica da experiência de sabores amargos e a expressão facial típica das pessoas que vêm a ser qualificadas como "amargas", uma vez que em ambos os casos é mais usual observarmos o semblante fechado.

Por fim, Silva (2006) menciona os estudos de Lakoff e Johnson (1980) sobre as metáforas convencionalizadas para mostrar como, após construído o mapeamento de um domínio para outro e estruturada a significação metafórica de uma expressão, esta pode ser submetida a um processo de convencionalização - essencialmente pragmático e social - que poupará o falante de ter que percorrer a ponte figurativa que une os dois domínios a cada uso da expressão em questão. Nas palavras de Silva (2006, p. 152), a "metáfora convencionalizada é a que os falantes são capazes de utilizar sem terem (ou sem precisarem de ter) consciência da sua natureza metafórica, isto é, sem terem que activamente construir o domínio alvo em termos do domínioorigem". Segundo ele, algumas metáforas estão tão convencionalizadas que seu domínio de origem de certa forma perdeu-se de vista no campo de uso. Um exemplo disso seria a palavra músculo, cujo significado literal original era pequeno rato, designando metaforicamente certo órgão humano cujas fibras apresentam uma similaridade com ratos recém-nascidos. Atualmente, é plausível que, para a maioria dos falantes de português, músculo seja o designador literal de um órgão humano e não de um animal. 
$\mathrm{Na}$ seção seguinte, apresentaremos uma análise do advérbio português "literalmente" segundo o modelo de Sweetser (1990) esboçado aqui. A análise tomará por base exemplos construídos a partir do uso vernacular, bem como de casos extraídos na internet.

\section{Análise do advérbio "literalmente"}

O advérbio de modo "literalmente" é constituído a partir da palavra literal, usada desde o século XVI, tem suas origens no latim com o significado "de letras; formado com letras", (MACHADO, 1993, p. 430), denotando algo que está escrito. Letra é outra palavra de origem latina que designava um "sinal; carácter de escrita”, usada desde o século XIII na língua portuguesa (MACHADO, 1993, p. 409). O advérbio "literalmente" foi formado por um processo morfológico de derivação sufixal, adicionando-se ao adjetivo literal o morfema gramatical -mente, criando-se assim um advérbio de modo que denota o ato de ler ou escrever algo, letra a letra.

Considerem-se as sentenças a seguir:

(1) João copiou o texto "literalmente".

(2) João está "literalmente" cansado.

Em (1) o uso do advérbio é literal no sentido em que respeita a etimologia da palavra. A interpretação que usualmente faríamos é a de que o João copiou o texto tal como estava escrito, ou seja, "letra por letra". Já a sentença (2), se avaliada à luz do significado etimológico, não pode ser considerada de modo literal, isto é, não pode ser interpretada como "João está cansado letra por letra", pois o uso literal do advérbio "literalmente" pressupõe um ato de escrita. Pode-se assumir que "literalmente cansado" significa ao ouvinte que a palavra cansado está sendo usada em seu sentido mais pleno (mais concreto), isto é, João está cansado "com todas as letras" da palavra cansado. Nesse caso, é fácil perceber que o significado do advérbio foi estendido, de modo que o contexto de escrita pode ser dispensado. "Literalmente" aqui foi elevado ao domínio epistêmico, enfatizando um significado e não mais a palavra em si mesma.
Cabe observar, todavia, que não existe correlação necessária entre a definição etimológica e o sentido literal. Segundo a teoria da prototipicidade de Rosch $(1973,1978)$ tal como retomada por Sweetser (1990) e Silva (2006), o significado mais prototípico de uma palavra geralmente corresponde ao significado mais usual ou ao mais concreto entre os mais usuais. $\mathrm{Na}$ língua portuguesa contemporânea, o significado metafórico e epistêmico de "literalmente" foi convencionalizado, de modo que seu uso passou a ser mais usual que seu significado literal, isto é, o uso de "literalmente" como sinônimo de "copiar letra a letra" tornou-se cada vez menos motivado. Diante disso, a função figurada desse advérbio assumiu uma posição mais prototípica e, por essa razão, é natural que os falantes de português interpretem a sentença (2) como uma sentença literal, ou seja, interpretem "João está literalmente cansado" como se referindo ao fato de João estar muito cansado, sendo tal interpretação tomada como o significado próprio de estar cansado. "Literalmente" passa a ter a interpretação de "realmente", "de fato", apontando, a partir do plano epistêmico, para o sentido mais concreto da palavra que está sendo modificada. No exemplo (2), "literalmente" é usado para dizer que não há um exagero na expressão, mas sim um uso real, verdadeiro da mesma.

O processo de variação semântica e sua relação com a transformação dos protótipos é abordado por Silva (2006) e foge ao escopo deste trabalho entrar em seus pormenores. Entretanto, é possível observar uma relação entre tal processo e o modelo de mudança semântica de Sweetser (1990). O sentido etimológico de "literalmente" claramente corresponde a uma experiência concreta. Copiar um texto letra a letra é uma experiência socio-física, situada no nível de conteúdo. Estar muito cansado também é uma experiência concreta, mas usar "literalmente" para se referir à intensidade dessa experiência exige uma abstração do sentido original do advérbio em questão. Podemos, então, dizer que um uso metafórico do termo foi necessário para estendê-lo de um contexto a outro, e essa operação ocorre no nível epistêmico, pois ela estabelece um paralelo entre uma cópia ser 
fidedigna ao seu modelo original (sentido concreto) e uma expressão ser fidedigna à sua significação original, ou melhor, à sua significação mais prototípica (pois, como vimos, o sentido mais prototípico não necessariamente é o sentido etimológico). Isso faz com que usos abstratos de "literalmente", isto é, usos que são interpretados pelo fato de uma expressão ser fiel ao seu significado mais prototípico, sejam tomados pelos falantes como se expressassem um uso literal, visto que o significado mais prototípico do termo "literalmente" passou a ser não mais o de "copiar letra a letra", mas o de designar sentidos mais prototípicos do termo sob seu escopo. Assim, em "João está literalmente cansado", o advérbio indica que o cansaço de João não é metafórico (ou então, como visto anteriormente, que seu cansaço é intenso, é um cansaço de fato, efetivo. Fica claro, assim, que é graças a um processo de extensão metafórica que o termo "literalmente" adquire seu sentido de indicar que a expressão modificada não está sendo usada de modo metafórico e, portanto, está no plano concreto.

$\mathrm{Na}$ construção do significado usual do advérbio "literalmente" observamos, portanto, dois processos: uma extensão metafórica que o eleva do uso concreto para o uso epistêmico e uma convencionalização que torna o uso epistêmico mais prototípico que o uso concreto. A convencionalização do sentido epistêmico de "literalmente" é ainda facilitada pela percepção de uma analogia entre a oposição de letra e figura e a oposição entre "uso literal" e "uso figurado". O primeiro designa o uso mais estrito, tal como letras são mais estritas do que figuras.

O uso metafórico abre ainda possibilidade para construção de novos significados. Considere-se a sentença:

(3) Cuidado ao pegar a xícara, pois o café está "literalmente" quente.

A interpretação prototípica de "literalmente" nessa sentença é a de que o adjetivo quente está sendo utilizado de modo literal. Tal interpretação ocorre em nível epistêmico, construída a partir da analogia indicada no parágrafo anterior. Ocorre, entretanto, que a interpretação prototípica da palavra quente nesse contexto já seria sua interpretação literal, havendo redundância no uso epistêmico do advérbio "literalmente". Essa redundância permite que o advérbio adquira uma função intensificadora. Nesse caso, "o café está literalmente quente" não significa apenas que ele está "realmente quente", mas também que está "muito quente". O uso do advérbio como intensificador corresponde àquilo que Sweetser (1990) apontou como domínio performativo.

Considere-se a sentença a seguir:

(4) João saiu uma fera daqui, "literalmente".

Em (4), evidentemente, não é o caso de João ter-se transformado em uma fera ao sair, pois a expressão "saiu uma fera" não admite interpretação literal nesse contexto. O advérbio "literalmente" está sendo usado aí para intensificar o proferimento. "Sair uma fera" é necessariamente uma metáfora, o que contradiz o uso mais prototípico de "literalmente" (indicar que a expressão modificada é literal). Trata-se, portanto, de um uso que esvazia momentaneamente o advérbio "literalmente" de seu sentido usual e projeta uma função relacionada ao ato de proferimento.

A questão fica um pouco mais complexa em casos nos quais a expressão modificada admite interpretação ambígua, como era o caso em (2). Em "João está literalmente cansado", o advérbio pode ser interpretado tanto como um indicador da literalidade de cansado quanto como um intensificador de cansado caso este esteja sendo utilizado de modo claramente metafórico naquele contexto. A função usual de "literalmente" é indicar que a expressão que ele modifica está sendo usada em sentido literal, entretanto, se tal expressão não admite uma interpretação literal (ou admite uma interpretação ambígua), o uso de "literalmente" pode assumir um caráter performativo e sua função passa a ser a de intensificar a expressão metafórica que está sendo modificada. Se o falante tivesse proferido a frase "João está literalmente cansado de suas piadas", o advérbio é necessariamente performativo, pois dificilmente se encontraria um contexto no qual alguém estivesse 
fisicamente cansado de "piadas". Assim, a sentença (2) admite tanto a interpretação usual/epistêmica quanto a interpretação performativa, mas não admite a interpretação concreta do advérbio "literalmente".

Em suma, pode-se constatar que o advérbio "literalmente" pode operar nos três níveis descritos por Sweetser (1990). No nível do conteúdo, ele opera a partir de seu significado concreto e original, denotando transcrição textual. A partir de uma operação metafórica sobre esse nível, a qual efetua uma analogia entre a fidedignidade de uma transcrição ao texto original e a fidedignidade de uma expressão ao sentido prototípico, o advérbio pode ascender ao nível epistêmico e denotar a literalidade da expressão modificada, isto é, denotar que esta não está sendo utilizada em sentido metafórico. O uso epistêmico do advérbio consiste atualmente em seu emprego mais corrente na língua portuguesa. E, por fim, é possível esvaziar, performativamente, tanto o sentido concreto quanto o sentido epistêmico do advérbio "literalmente" e utilizá-lo como um intensificador de outras expressões. A função intensificadora desse advérbio depende de que a expressão sobre a qual ele opera não admita interpretação literal no contexto em questão ou, no mínimo, que admita uma interpretação ambígua entre o literal e o metafórico.

O uso vernacular de "literalmente" confirma a difusão dos sentidos mais abstratos do advérbio, de forma que o modo performativo pode ser facilmente encontrado até mesmo em matérias jornalísticas. Considerem-se os seguintes exemplos, extraídos do site "Errado, Literalmente" (2015):

(6) $O$ bicho literalmente pegou [na Vila Belmiro].

(7) $\mathrm{Hj}$ tô literalmente dormindo desde que acordei...!

(8) Adorno é literalmente o braço direito de reitor Rodas.

(9) Bomba! (Literalmente) Adversários de Anderson e Minotauro são flagrados no antidoping...

(10) Dentro das piscinas, o Brasil literalmente lavou a alma até aqui.
(11) Vou acabar este verão literalmente uma bolinha.

(12) O zagueiro está literalmente colado no atacante.

No exemplo (6), a metáfora "O bicho pegou", precedida pelo advérbio "literalmente", dificilmente seria utilizada em sentido factual no contexto de um jogo de futebol. Nesse caso, o advérbio visa intensificar a interpretação da expressão popular "o bicho pegou" através de uma construção que, de outro modo, soaria absurda. A sentença poderia ser facilmente substituída por "O bicho pegou pra valer". Algo similar ocorre no exemplo (12), por ser improvável que um jogador esteja de fato "colado" em outro durante uma partida.

No exemplo (7), como no anterior, uma situação absurda é evocada, aqui na forma de uma contradição semântica, para constatar a intensidade de sono sentido por quem proferiu a sentença. A sentença "Hj tô literalmente dormindo desde que acordei” não apenas é improvável, como também é impossível de ser interpretada "literalmente", pois acordar implica 'não mais estar dormindo'. Tal construção compele o ouvinte a interpretar a sentença como sinônima de "Estou quase dormindo desde que acordei", de modo que o advérbio intensifica o sentido de "estar dormindo" na medida em que enfraquece o de "estar acordado".

Situação similar ocorre nos exemplos (8) e (10), nos quais as expressões "Adorno é. o braço direito" e "o Brasil... lavou a alma" não admitem interpretações literais, forçando interpretações performativas intensificadoras a fim de que se preserve o sentido das sentenças. Nesses casos, uma interpretação não metafórica conduziria a uma contradição semântica, mas evocaria uma atmosfera fabulesca que condiz com o contexto de proferimento de ambas. Também na sentença (11), ao comparar-se "literalmente" [com] "uma bolinha", o enunciador chama a atenção para o fato de que sua forma física pode "literalmente" ser similar à de uma bola, mas não que ele próprio se tornará uma ao final do verão.

Já o exemplo (9) apresenta uma situação especialmente inusitada. A expressão Bomba! é 
comumente utilizada nos meios jornalísticos de modo metafórico para designar notícias especialmente surpreendentes ou "estrondosas". Seria de se esperar que "Bomba! (Literalmente)" designasse uma notícia relacionada a bombas ou explosões, mas, nesse caso, trata-se de um relato de uso de doping, metaforicamente chamado no Brasil de "bomba", onde se diz que usa "bomba", quem faz uso de anabolizantes. No caso em tela, o advérbio "literalmente" foi usado para, além de intensificar a manchete, designar um sentido metafórico (doping) diferente do sentido metafórico mais comum (notícia surpreendente). Em nenhum caso, todavia, fez-se referência ao sentido literal do termo "bomba".

Esses casos demonstram 0 poder do deslocamento metafórico no uso vernacular, sendo capaz de alterar performativamente até mesmo o sentido de termos usados para designar aquilo que não é metafórico num dado contexto. A seção a seguir buscar exemplificar o emprego do advérbio buchstäblich em alemão, correspondente ao nosso "literalmente", a fim de verificar translinguisticamente a consistência da explicação proposta pelo modelo teórico aqui focalizado.

\section{Análise do advérbio buchstäblich}

Podemos aqui levantar uma questão, a saber, se essa explicação seria sustentada translinguisticamente. Assim, buscamos nesta seção verificar se esse comportamento do advérbio ocorreria em outras línguas além do português.

A tradução usual de "literalmente" para o alemão é buchstäblich. Ambas as palavras provêm de línguas que fazem parte da família linguística indoeuropeia, sendo o alemão do ramo das línguas germânicas e o português do ramo das línguas românicas ou latinas.

A palavra buchstäblich é formada por meio de uma derivação que transforma o sintagma der Buchstabe ("a letra") de um adjetivo a um advérbio de modo. Como se pode observar, a relação original é basicamente a mesma que a do advérbio correspondente em português. Em Buchstabe, a referência eram as runas das línguas protogermânicas e, em literal ${ }_{2}$ a referência eram as letras do alfabeto latino. A palavra Buchstabe, como base de buchstäblich, mudou de significado e passou a denominar exclusivamente letras latinas. Buchstabe compõe-se de das Buch ("o livro") e der Stab ("o bastão"). No seu sentido antigo, das Buch referia-se a tábuas de pau de faia (die Buche) usadas para receber a escrita, como antecessoras do livro moderno (PFEIFER, 1993, p. 178). Der Stab ("o bastão") referese a um traço vertical que as runas das línguas germânicas possuíam. A palavra aparece no século VIII nas línguas nórdicas arcaicas e a composição existia no alto-alemão antigo (buohstab) e, logo, no alto-alemão médio (buochstabe) (PFEIFER, 1993, p. 180). Naquele período, o significado já havia mudado para referir-se exclusivamente às letras do alfabeto latino, utilizadas na escrita dos livros da época, quando as runas haviam perdido a importância. Posteriormente, o adjetivo e advérbio modal chegaram a ter o significado de "literal(mente)" e "real(mente)", correspondendo ao sentido restrito das palavras.

Remetendo à análise anteriormente proposta, podemos observar usos do advérbio buchstäblich nos três níveis descritos por Sweetser (1990), similarmente ao que ocorre na língua portuguesa. Como no exemplo (1) precedente, podemos observar o significado literal da palavra no nível de conteúdo na língua alemã:

(13) Martin hat den Text buchstäblich abgeschrieben.

Martin tem o texto "literalmente" copiado.

Ou seja, o texto foi copiado por Martin buchstäblich, letra a letra, tal como estava escrito. O significado etimológico da palavra é utilizado e respeitado. Entretanto, no alemão também ocorreu um processo de convencionalização da metáfora e esvaziamento semântico do significado concreto. Ao longo do tempo, o significado literal, originalmente etimológico, tornouse menos usual que seu uso metafórico e a experiência sóciofísica, que alimentava a semântica de buchstäblich no nível de conteúdo, se tornou menos 
prototípica que a experiência epistêmica. Considere-se o exemplo a seguir:

(14) Es ist buchstäblich heiß hier.

Aqui está "literalmente" muito quente.

A significação epistêmica é utilizada nesse exemplo, indicando metaforicamente o significado literal da palavra quente (heiß). Exceto se o contexto indicar que quente possui uma interpretação metafórica, o que (14) expressa é que está de fato quente no ambiente de proferimento. Nesse caso, não se pode falar do significado literal de buchstäblich, mas apenas do significado literal de heiß. O exemplo (14) mostra, portanto, que a já mencionada analogia com a cópia fidedigna do sentido concreto também existe na língua alemã. Há de se observar que, como em (2), a frase (14) também admite uma interpretação ambígua entre o modo usual epistêmico e o modo performativo, mas não admite uma interpretação concreta do advérbio buchstäblich.

Quanto ao uso performativo, considere-se a sentença:

(15) Mit Wumms ${ }^{7}$ : wie Kraftklub und 8000 Fans die Arena buchstäblich zum Beben bringen.

Com força: como a Kraftklub e 8000 fãs a Arena, "literalmente", fazem tremer.

Com força: como a Kraftklub e 8000 fãs fazem a Arena tremer, "literalmente".

Nesse exemplo, como no exemplo (4), é evidente que a arena não tremeu no sentido literal do termo. O que realmente aconteceu foi que a Krafklub, um grupo musical alemão, realizou um show na Arena de Leipzig e animou os fãs de modo intenso, ou seja, buchstäblich tem sentido exclusivamente metafórico e assume função de intensificador, podendo ainda veicular a avaliação do enunciador sobre o evento. Nota-se desse modo que, assim como seu correspondente no português, buchstäblich pode operar nos três domínios definidos por Sweetser (1990).

\section{Considerações finais}

Neste trabalho, discutimos e investigamos os advérbios "literalmente" e buchstäblich, buscando entender alguns de seus diferentes usos a partir de um modelo teórico semântico-cognitivista. A partir de Castilho et al. (2008), constatamos que os advérbios configuram uma classe de palavras que possui a propriedade de produzir modificações semânticas em palavras pertencentes a classes mais amplas que os substantivos, usualmente modificados por adjetivos. Em seguida, apresentamos o modelo de Sweetser (1990) e buscamos explicar os diferentes usos de "literalmente" e buchstäblich a partir de uma análise de mudança semântica.

No nível sincrônico, essa mudança se estabelece em três domínios: concreto, epistêmico e performativo. O plano concreto é o da realidade sóciofísica, que determina as relações semânticas no nível do conteúdo. As relações sóciofísicas podem ser estendidas para o plano epistêmico através de construções metafóricas que determinam relações semânticas em seu aspecto lógico, ou de processos inferenciais. Por fim, no plano performativo, as relações estruturadas nos níveis anteriores determinam a semântica do ato de fala. Como visto, não são raras as vezes em que ouvimos sentenças nas quais esses advérbios são usados em sentidos não prototípicos e o uso performativo permite que advérbios sejam semanticamente utilizados para modificar inclusive substantivos (CASTILHO et al., 2008).

Constatamos, assim, que os exemplos abordados se aplicam aos três domínios, os quais nos permitem sustentar uma análise translinguística, demonstrando a pertinência do modelo e sua capacidade de generalização. Além disso, vimos que tanto "literalmente" quanto buchstäblich possuem um desenvolvimento etimológico similar, com origem da significação ligada aos símbolos da escrita e da letra, tendo atualmente se orientado à designação de

\footnotetext{
7 Wumms é uma onomatopeia intensificadora e quer dizer algo como "muita força, muita energia", ou seja, Mit Wumms quer dizer "com muita força, com muita energia".
} 
sentidos restritos - mais prototípicos - das palavras que modificam, bem como ao uso performativo com função intensificadora. Esse paralelo evidencia uma regularidade que, acreditamos, corrobora a tese defendida por Sweetser de que há um substrato cognitivo universal operando na mudança da língua, e que a metáfora desempenha uma participação importante nesse processo.

\section{Referências}

CASTILHO, A. T. de et al. O advérbio. In: CASTILHO, A. T. de (Coord.); ILARI, R.; NEVES, M. H. de M. (Org.). Gramática do português culto falado no Brasil. Campinas: Editora da Unicamp, 2008. v. 2. (Classes de palavras e processos de construção). p. 403-499.

ERRADO, LITERALMENTE. Disponível em: $<$ http://erradoliteralmente.tumblr.com/>. Acesso em: 27 ago. 2015.
LAKOFF, G.; JOHNSON, M. Metaphors we live by. Chicago/London: The University of Chicago Press, 1980.

MACHADO, J. P. Dicionário etimológico da língua portuguesa: F-L. Lisboa, 1993.

PFEIFER, W. Etymologisches wörterbuch des deutschen: A-L. Berlin: Akademie-Verlag $\mathrm{GmbH}$, 1993. $1665 \mathrm{p}$.

$\mathrm{ROSCH}, \mathrm{E}$. On the internal structure of perceptual and semantic categories. In T. E. MOORE (Ed.), Cognitive development and the acquisition of language. New York: Academic Press, 1973.

Principles of Categorization. in: $\mathrm{ROSCH}, \mathrm{E}$. and LLOYD, B. B. (eds), Cognition and categorization 27-48. Hillsdale, NJ: Lawrence Erlbaum.

SILVA, A. S. da. O mundo dos sentidos em português: polissemia, semântica e cognição. Coimbra: Edições Almedina, 2006. p. 392

SWEETSER, E. From etymology to pragmatics. Metaphorical and cultural aspects of semantic structure. Cambridge: Cambridge University Press, 1990. p. 174

\section{COMO CITAR ESSE ARTIGO}

DEOSTI, Aline et al. Análise do processo de mudança semântica dos advérbios literalmente e buchstäblich a partir do modelo semântico-cognitivo de Eve Sweetser. Signo, Santa Cruz do Sul, v. 41, n. 71, maio 2016. ISSN 19822014. Disponível em: <https://online.unisc.br/seer/index.php/signo/article/view/6919>. Acesso em: doi: http://dx.doi.org/10.17058/signo.v41i71.6919. 